\title{
Reseña sobre el libro "Cómo negociar con éxito: el método de avanzada para construir tratos justos para todos"
}

\author{
"How to negotiate successfully: the advanced method to build fair deals for all"
}

Janeth Lohany Lorenzo Cordero ${ }^{a}$

\begin{abstract}
:
How to negotiate successfully: the advanced method of building fair deals for all" is a book that proposes a new way of negotiating in innovative, creative and ethical ways. Through an easy and simple process, the Albrecht brothers radically change the old conception of generating agreements, with a proposal that satisfies the interests that are sought in a negotiation through the search for value and that can also be applied to various aspects of the everyday life, not only in the business world. The authors guide the reader to lose their fear of negotiating.
\end{abstract}

Keywords:

Negotiation, agreement, value added

\section{Resumen:}

“Cómo negociar con éxito: el método de avanzada para construir tratos justos para todos" es un libro que propone una nueva forma de hacer negociaciones de manera innovadora, creativa y ética. A través de un proceso fácil y sencillo, los hermanos Albrecht cambian radicalmente la concepción antigua de generar acuerdos, con una propuesta que satisface los intereses que se buscan en una negociación a través de la búsqueda de valor y que además se puede aplicar a diversos aspectos de la vida cotidiana, no solamente en el mundo empresarial. Los autores guían al lector para perder el miedo a realizar una negociación.

\section{Palabras Clave:}

Negociación, acuerdo, valor añadido

\section{Introducción}

Los hermanos Karl y Steve Albretch, empresarios exitosos alemanes, comparten su obra "Cómo negociar con éxito: el método de avanzada para construir tratos justos para todos" que contiene nueve capítulos y es de la editorial Granica.

En la primera parte del libro se pone sobre la mesa uno de los temas más rudos y temidos por la mayoría de las personas: la negociación. En distintos momentos de la vida, todos nos hemos enfrentado a este proceso, desde una negociación familiar hasta gestionar grandes acuerdos comerciales. Es importante mencionar la forma tradicional en la que este proceso se ha llevado desde hace tiempo. Los negociadores duros, los cuales son el típico estereotipo al que todos aspiramos a convertimos algún día, es aquella persona que durante el momento de la negociación está decida a intimidar todo el tiempo a la otra parte negociadora, pues lo ve como un oponente. Generalmente, suele hacer críticas duras sobre el tema, jugar al papel de ostentación de sus logros personales para llegar a hacer sentir al otro sujeto como si le estu viera haciendo un favor al regalarle unos minutos de su tiempo. Sin embargo, esta forma de negociar ha evolucionado con el paso de los años, existe otra forma diferente de jugar al "ganador-perdedor", que es cuando una persona logra obtener todo lo que quiere a costa de los intereses de la otra persona, y del típico intento de buscar un "ganarganar", que se ha convertido en un intento hostil de querer engañar a las partes negociadoras quiénes portan una máscara de bondad y generosidad.

La nueva forma de hacer tratos es mediante la Negociación de Valor Añadido (NVA), que tiene un enfoque en el cual las partes interesadas aumentan en forma cooperativa el valor que pueden otorgar. Los

Autor de Correspondencia, Universidad Autónoma del Estado de Hidalgo, https://orcid.org/0000-0001-5565-9716, Email: 1o216284@uaeh.edu.mx 
beneficios de este concepto son añadir valor en lugar de reducirlo, fomentar un ambiente agradable durante la negociación, permite obtener una visión más amplia y ayuda a mantener el control todo el tiempo.

En la segunda parte, se aborda el concepto del valor añadido, así como distintas definiciones que conforman una negociación. Se debe tener una marcada diferencia de los distintos componentes que conforman una negociación, primero tener en cuenta el concepto de acuerdo, que es, el intercambio de valor entre dos o más partes, dicho valor puede ser un intangible o tangible que puede comercializarse. Por otro lado, se encuentran los intereses que son aquellas necesidades, deseos 0 aspiraciones a las que se pretenden llegar a través de un acuerdo. La negociación es el proceso que se realiza para llegar al intercambio de valor y, por último, se encuentran las opciones, que son diversas maneras de presentar los elementos de valor que se incluyen en una negociación.

El proceso de la negociación con valor añadido, comienza con tener una idea clara de 6 los intereses que se tienen por ambas partes, para ello, se puede basar en una ventana de intereses, donde en un cuadrante se coloquen los intereses subjetivos tanto de lo que queremos como de lo que quiere la otra parte con la que negociamos, y en otro cuadrante se escriben los intereses objetivos que buscan ambas partes.

Después, se identifican las opciones que se tienen para satisfacer los intereses mediante la elaboración de un árbol de opciones, en donde se tiene cinco ramas correspondientes a dinero, propiedad, acciones, derechos y riesgos. Posteriormente, se realizan diversos paquetes que sean creativos y que contengan elementos de valor para las partes negociadoras. Finalmente se selecciona el mejor acuerdo y se perfecciona.

El tercer capítulo hace referencia a lo acostumbrados que estamos a tener miedo a la negociación, derivado al temor a perder algo, ya que de manera histórica se percibe a este proceso como un ganar-perder, es decir una persona tiene que perder algo para que la otra gane. Sin embargo, no tiene que ser de esta manera si utilizamos el método de valor añadido. Aunado a esto, existen diversos tipos de negociadores que debemos conocer, se encuentran desde el estilo bulldog que son agresivos y dominantes, el zorro que suele ser manipulador para que todo salga a su favor, el ciervo que es pasivo y el creador de cuervos, que es el tipo de negociador ideal que busca otorgar y obtener valor de una negociación, de manera ética y profesional. Los hermanos Albrecht, abordan en el cuarto capítulo el interés propio, el cual, para defen derlo en una negociación con valor añadido, es importante establecer normas de conducta que sirvan como base durante todo el proceso y que ambas partes las acaten. Aunque, no debemos confundir la defensa del interés propio con la idea de que la otra parte negociadora deba perder algo, es por ello que se deben considerar los intereses de ambas partes por igual. En este sentido, existen tres objetivos que se pueden satisfacer dentro de una negociación: primero satisfacer una necesidad, segundo, resolver un problema $y$, en tercer lugar, añadirvalor. Es importante mencionar que para poder conocer y determinar los intereses de ambas partes, se debe escuchar de manera activa, ser abierto y no interrumpir cuando una persona esté hablando.

La quinta parte del libro está dedicada a descubrirvaloren toda negociación, que si bien, estamos acostumbrados a percibir como valor al dinero de manera literal, existen otras maneras de obtener valor, por ejemplo, los intangibles, en esta categoría se encuentra la propiedad intelectual sobre una patente, alguna innovación de un software o una base de datos con información importante. Una pregunta común sobre el tipo de bienes intangibles es ¿cómo determinar su valor?, la respuesta es simple, el valor de un intangible dependerá de su capacidad de comercialización, es decir, del juego de la oferta y la demanda, entre más demanda exista, mayor será su valor.

Para tener una idea más clara sobre el posible valor que tiene una negociación se sugiere realizar un árbol de opciones, que es un diagrama que concentra en cada una de las ramas algún tipo de valorque probablemente tenga la otra parte negociadora que le pueda servir a usted. De esta manera, cuando visualice los posibles acuerdos que se pueden generar, mantendrá presente el valor que desea dar y recibir.

El sexto apartado hace referencia a la creación de paquetes de acuerdos. Una vez que se tiene la ventana de intereses y el árbol de valor, el siguiente paso es crear diversos paquetes de posibles acuerdos que contengan un valor para otorgar y otro para recibir, ya sea tangible 0 intangible, y que estén ligados con los intereses que esperan cubrir ambas partes, ya sea por deseo o necesidad. En este punto es importante mantener un equilibrio entre las partes negociadoras, ya que se tiene primero que ofrecer algo de valor para recibir lo mismo a cambio, de esta forma ambas partes obtendrán un sentimiento de agradecimiento mutuo en lugar de sentir la pérdida de algo. Además de generar diversos tipos de paquetes, que sean creativos y heterogéneos para poder ofrecer muchas opciones y poder elegir la que más convenga y agrade a los negociadores.

El capítulo siete plantea los principales problemas dentro de una negociación, los cuales generalmente, surgen por falta de empatía, por exceso de estrés, fatiga, mala comunicación o la personalidad de los negociadores. Para evitar este ambiente hostil que conlleva a tener un conflicto de intereses, se puede fomentar un grado de formalidad apropiado a la situación, concentrarse en las necesidades, permitir a todas las partes el poder 
expresarse de manera libre y alentar a mantener una discusión abierta.

Si bien, pensamos en una negociación favorable para todas las partes, en algunas ocasiones es importante saber decir no, aunque esto no significa que nunca se volverá a negociar con esa persona o empresa, tal vez, con las condiciones actuales resulta poco conveniente el valor que nos otorgan. En estas condiciones, sería recomendable saber decir no y dejar las puertas abiertas en caso de que en un futuro se pueda presentar de nuevo una oportunidad de negociación.

En el apartado ocho, se aborda el último paso de la Negociación de Valor Añadido (NVA) que es llegar al apretón de manos. Cuando se ha encontrado el equilibrio adecuado entre los intereses propios y de la otra parte, así como el consenso del valor que se va a dar mediante un paquete de acuerdos, es vital pulir todos los detalles posibles para llegar a cerrar la negociación. Aun cuando uno desee que todas las personas con las que negociamos actúen de buena fe, existen diversos consejos a seguir para evitar artimañas posteriores al apretón de manos.

Entre las emboscadas más utilizadas se encuentran las letras chiquitas al final del documento que lo comprometen a ciertas acciones no negociadas, los gastos ocultos (que pueden ser pequeños costos de envío o asumir pérdidas en caso de tener errores en los productos), así como dejar entre paréntesis partes del acuerdo que posteriormente podrían generar descontento. La mejor sugerencia para reaccionar de forma objetiva ante estas situaciones, es volver a revisar la ventana de los intereses y el árbol de valor para afinar el acuerdo o simplemente dar tiempo para recalcular los beneficios y costos del nuevo acuerdo. Finalmente, la última parte son reflexiones finales, ya que, después de haber aprendido el proceso de la negociación con valor añadido lo más recomendable es ponerlo en práctica tantas veces como sea posible, ya que la práctica hace al maestro y de esta manera se puede pulir la forma en que somos negociadores.

Hay que recordar ser empático en todo momento, tener confianza en el proceso del valor añadido y saber que se puede aplicar en todas las áreas de la vida cotidiana.

\section{Referencias}

[1] Albrecht, K. y Albrecht, S. (2014). Cómo negociar con éxito, el método de avanzada para construir tratos justos para todos. Argentina: Granica. 